\title{
THE CLASSIFICATION OF SNOW METAMORPHISM
}

\author{
By R. A. Sommerfeld \\ (U.S. Forest Service, Rocky Mountain Forest and Range Experiment Station, * Fort Collins, \\ Colorado 8052 I, U.S.A.) \\ and E. LaCihapelle \\ (Department of Atmospheric Sciences, University of Washington, Seattle, Washington 98105, \\ U.S.A.)
}

\begin{abstract}
A new classification of snow on the ground is based on the major physical processes involved in the metamorphism of a snow cover. The major divisions are based on (I) the mechanical damage to snow crystals during precipitation, (II) the transport of water vapor at constant temperature because of surfaceenergy differences, (III) the transport of water vapor along a thermal gradient, and (IV) firnification because of melting and refreezing, and pressure consolidation.

RÉsumé. La classification du métamorphisme de la neige. Une nouvelle classification de la neige au sol est basée sur les principaux processus physiques du métamorphisme d'une couverture de neige. Les divisions principales sont basées sur (I) les dommages mécaniques causés par les cristaux de neige pendant la précipitation, (II) le transport de la vapeur d'eau à température constante dû aux différences d'énergie superficielle, (III) le transport de vapeur d'eau le long d'un gradient thermique et (IV) la formation de névé dûe à la fonte au regel de même qu'au tassement.

Zusammenfassung. Die Klassifikation von Schneemetamorphose. Eine neue Klassifikation von liegendem Schnee geht von den wichtigsten physikalischen Vorgängen bei der Metamorphose einer Schneedecke aus. Die Hauptgliederung beruht auf (I) der mechanischen Beschädigung der Schneekristalle beim Niederschlag, (II) dem Transport von Wasserdampf bei konstanter Temperatur infolge von Unterschieden in der Oberflächenenergie, (III) dem Transport von Wasserdampf längs eines Temperaturgradienten, und (IV) der Verfirnung infolge von Schmelzen und Wiedergefrieren sowie der Druckverfestigung.
\end{abstract}

\section{Definitions}

A certain amount of confusion exists in the classification of metamorphosed snow. For example, the term crystalline, which is a precise, scientific term, is misused by many workers in the field. A solid is crystalline if its atoms are arranged in an orderly array. Under this definition, all ice found in nature is crystalline whether it consists of snow-flakes, metamorphosed snow, lake ice, or ice cubes in a glass. Thus, it is nonsense to speak of snow grains losing or gaining crystalline character. A crystal may be rounded, partly faceted, or faceted, according to the degree to which the crystal faces are developed.

Structure in the crystallographic sense refers to the molecular arrangement in the crystal. In common usage structure also refers to the layering or stratigraphy of the snow cover. Because the scale of these two usages is very different, no confusion should result. We suggest texture to describe the relationships among the snow crystals.

The snow cover is an aggregate of ice crystals, and its texture is polycrystalline. The individual crystals in a polycrystalline material are called grains and are separated by grain boundaries. In snow, the term grain is more loosely defined as one of the obvious sub-units which make up the snowpack. Thus, in speaking of snow, the term grain does not mean the same as the very specific term in metallography. Special techniques, which are too cumbersome for use in the field, are necessary to make the grain boundaries visible. The precise locations of the grain boundaries would give an unnecessarily detailed description of the snowpack for normal purposes. If the snow is not bonded, the separation between the grains is real and the identification of separate grains is easy and precise. Once the snow becomes bonded into its usual, complex, three-dimensional network, the placement of the boundaries between grains becomes increasingly arbitrary and inexact with increasing density. Furthermore, the exact

* Central headquarters maintained in cooperation with Colorado State University, Fort Collins, Colorado, U.S.A. 
measurement of the sizes of the complicated shapes of snow grains is much too tedious for any practical field routine. These distinctions do not have to be absolute, however, to be useful. The description of a snow layer as small, medium, or large grained has obvious meaning and is important in characterizing the condition of the snowpack.

The terms crystal and grain may be used interchangeably under certain circumstances. There are times when each grain is a single crystal, as in new snow and in some of the stages of metamorphism. On the other hand, a grain may be polycrystalline, or a single crystal may consist of more than one grain (Fig. I). The latter possibility becomes common only for advanced stages of firnification (see below). Even when the crystals and grains are very nearly identical, the arbitrary boundaries of the grains may not correspond exactly to the crystallographic boundaries between crystals. Unless the boundaries of the crystals are well defined, as when the crystal faces are well developed, the more general term grain should be used.

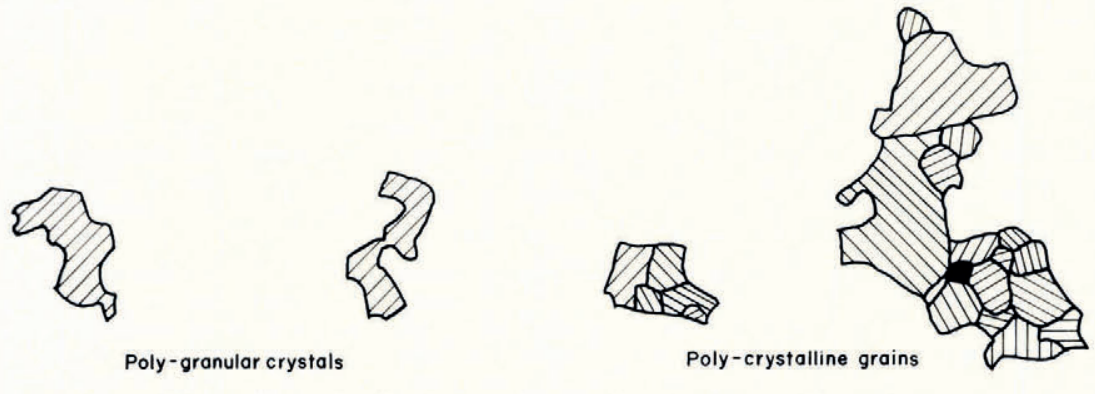

Fig. I. Examples of poly-gramular crystals and poly-crystalline grains.

\section{Previous classifications}

Existing schemes for classifying snow on the ground are based on the shapes of the snow grains. The "International classification for snow" (Canada. National Research Council, 1954) uses grain size and the presence or absence of facets and stepped surfaces to distinguish among snow types. Inadequate reference in this classification to the physical processes responsible for these external features often leads to confusion among snow observers. The explanations of the processes are sketchy and in some cases in error. The use of phrases like "lost its crystalline character" is unfortunate.

Eugster (1952) divided snow metamorphism into the categories: "destructive", "constructive", and "retrograde". The distinctions were based on whether the process formed or destroyed surface features such as dendrites, facets, and steps, but the emphasis was on the forms and not the processes.

Both the International and the Eugster classifications are essentially morphological. The major processes of snow metamorphism are sufficiently well understood today that a similar classification scheme for deposited snow may be framed on generic grounds. We feel that such a scheme is highly desirable at this stage in snow research. It will enable field workers to understand better the changes occurring in the snow, and to communicate their findings more easily to other workers both in snow research and in related fields.

\section{The physical bases of the classifications}

\section{Unmetamorphosed snow}

In our classification system (see p. 9-17), we idealize certain conditions which strongly affect the character of the snow cover. Any actual snow cover is influenced by some mixture of these idealized conditions. For instance, the first category "unmetamorphosed snow" has the divisions "no wind action" and "wind blown". Nature does not sharply divide these 
extremes. Snow is deposited under almost any possible wind speed, so a choice, involving considerable judgement, must be made about the importance of wind action on any given snow layer. The distinctions in this category are governed by a strictly mechanical criterion: whether or not the original snow crystals were badly broken or deposited in a relatively undisturbed fashion. We recommend the use of Magono and Lee's (1966) classifications for the sub-categories under "unmetamorphosed snow" with "no wind action".

The classification "surface hoar" is used to cover direct deposition of water vapor from the atmosphere on to the snow surface. Surface hoar and depth hoar share similarities of form, but surface hoar tends to develop as flat plates instead of the three-dimensional development characteristic of depth hoar. Once incorporated within the snow cover, surface hoar tends to resemble depth hoar and follows a similar metamorphic pattern.

\section{Equi-lemperature metamorphism}

We have divided the important metamorphic processes in below-freezing, seasonal snow cover between "equi-temperature metamorphism" and "temperature-gradient metamorphism". These terms approximately correspond to the commonly used terms, constructive and destructive metamorphisms. Because the current usage is not clearly defined, we propose new terms to avoid confusion. The idealized conditions, of equal temperature throughout the sub-freezing snow cover, or of a constant temperature gradient, do not exist in nature; but by understanding what would happen under idealized conditions, we can better understand what happens under the mixture of natural conditions. Actual classification should be based on the history of the snow cover if it is known.

We distinguish between equi-temperature and temperature-gradient metamorphism because different physical processes are important under the two idealized conditions. Under equi-temperature conditions, the water molecules move, largely by vapor diffusion (Hobbs and Mason, I964; Hobbs and Radke, 1967), to new positions to decrease the surface free energy. A system will change to a state of lower free energy if it can, and the lowest possible energy state of any given system is its equilibrium state.

We know that the surface energy is proportional to surface area in a given mass. Snow falls from the sky with many dendrites, needles, etc., which have very large ratios of surface area to mass, and thus high surface free energy per unit mass. If snow crystals are broken by strong wind action, the resulting small fragments, shards, and splinters have even higher total surface free energy for the same mass of material. During equi-temperature metamorphism there is a continuous decrease of surface free energy. Therefore, no basis exists for absolute divisions, and our divisions mark arbitrary points in the decrease of surface free energy.
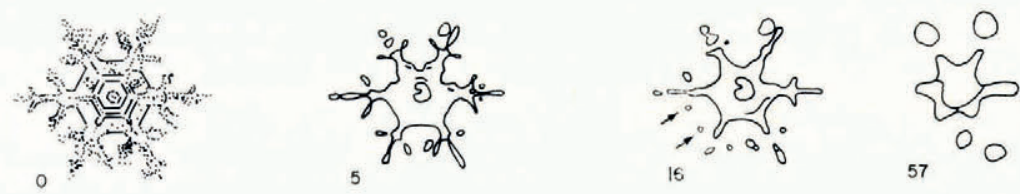

Fig. 2. The progress of equi-temperature metamorphism (the numbers are days). The temperature varied between $-2.5 \mathrm{C}$ and $11.5^{\circ} \mathrm{C}$. Drawn from photographs in Bader and others (1939).

An important point is that both time and temperature are major factors in determining the stage of metamorphism. If the snow is very cold, it will change very slowly; but if it is close to the freezing point, it can change very rapidly. Age alone will not determine the stage of metamorphism.

The first manifestation of equi-temperature metamorphism (stage II. A. I) is the decrease of curvature of the sharp points. This causes a distinct rounding and a loss of the fine markings on snow crystals (Fig. 2). This change is well illustrated by the careful work of Bader and 
others (I939) and Yosida (I955). In badly shattered, blown snow, this process may proceed very rapidly, even as the snow is being deposited. Thus blown snow may appear to skip this first step. A little later, but still within the same step, the small necks disappear, causing the snow crystal to lose most of its complicated shape and to break up into smaller grains with less total surface area (see Fig. 2). (The Eugster classification fails to recognize this process.)

We have defined a grain as the obvious sub-unit in the pack; during the first stage this means a snow crystal or a snow crystal fragment. When the small necks are destroyed, the grain size decreases and the number of grains increases.

During the next step in the metamorphic process (II. A. 2), the total surface area is further decreased as the grains become more equi-dimensional. Splinters and needles become shorter and wider; plates become thicker while their major diameters decrease. These first stages are equivalent to Eugster's (r 952) "destructive metamorphism".

For grains of the same shape, the smaller the size the larger the ratio of surface area to mass. Therefore, surface energy decreases further as the smaller grains disappear and the larger grains grow, leading to an increase in grain size and a decrease in grain number. This process is not as striking as the rounding of the grains, and while it occurs at earlier stages (arrows in Fig. 2), it is very difficult to see until the grains have fairly uniform shapes. We have used its apparent onset to mark a new step (II. B. I).

The various forms associated with depth hoar, such as the surface steps and the lattice and cup crystals, also result in a state of relatively high surface energy. Because of the large size of the crystals, the total surface energy is probably smaller than that of a corresponding mass of fine-grained snow. The large crystals can further reduce their surface energy by losing their surface features and becoming more equi-dimensional. If the temperature gradient necessary for the formation of depth hoar (see next section) is removed, the snow will undergo equitemperature metamorphism, eventually losing many of its facets and other surface features.

As the grains become more equi-dimensional and larger, the possible surface energy reduction available for further change decreases, and the process continually slows down (assuming constant temperature). Therefore, there is a practical limit to the size the grains can attain $(\approx \mathrm{I} \mathrm{mm})$ under sub-freezing and strictly equi-temperature metamorphism in the seasonal snow cover. Faceting visible at this stage may be evidence of slight temperature gradients.

\section{Temperature-gradient metamorphism}

The physical basis for the next major category, which is equivalent to Eugster's "constructive metamorphism", is the process of vapor transport along a strong thermal gradient. This is the process which leads to the formation of depth hoar. As with the distinction "no wind-strong wind", the distinction between temperature gradient and no temperature gradient is an idealization which is useful in clarifying the physical processes involved.

A thermal gradient in the snow cover provides the driving force for processes tending to decrease the gradient. As long as the gradient is maintained from the outside, as is the usual case in the snow cover, the processes act continually. The formation of depth hoar is the result of one of these processes: the transport of water vapor from warmer temperatures to colder (Quervain, 1958), by the complicated "hand to hand" mechanism described by Yosida (I955). Figure 3 shows three idealized grains in a snow cover during the formation of depth hoar. The thermal conductivity of air is much lower than that of ice, so the thermal gradient is steeper in the pore spaces, than in the individual grains. Because the top of grain $\mathrm{I}$ is warmer than the bottom of grain II, water sublimes from the top of grain I and deposits on grain II. Stated another way, the equilibrium vapor pressure at the top of grain $\mathrm{I}$ is higher than at the bottom of grain II; therefore, water vapor molecules diffuse from I to II. The same conditions exist between grains II and III, and so on throughout the layer. The grains will sublime at the top and grow at the bottom, finally causing well-oriented, pyramid-shaped grains. Sublimation 
etches the crystallographic grain boundaries, and may be a factor in the weak bonding which is a distinctive feature of this type of metamorphism. The stepped surface, which is important in identifying this stage, is a known feature of relatively rapid ice growth from the vapor.

The material from which this type of metamorphism starts has a strong effect on its progress. In new, fine-grained, porous snow, the action of surface energy will still be important, and there will be more grains on which the diffusing vapor can freeze. The effect is that the grains will not grow very large, and hollow pyramids will not be common (III. A. I-3). If temperature-gradient metamorphism starts from highly (equi-temperature) metamorphosed snow, there are a smaller number of crystals on which the vapor can freeze. The grains will

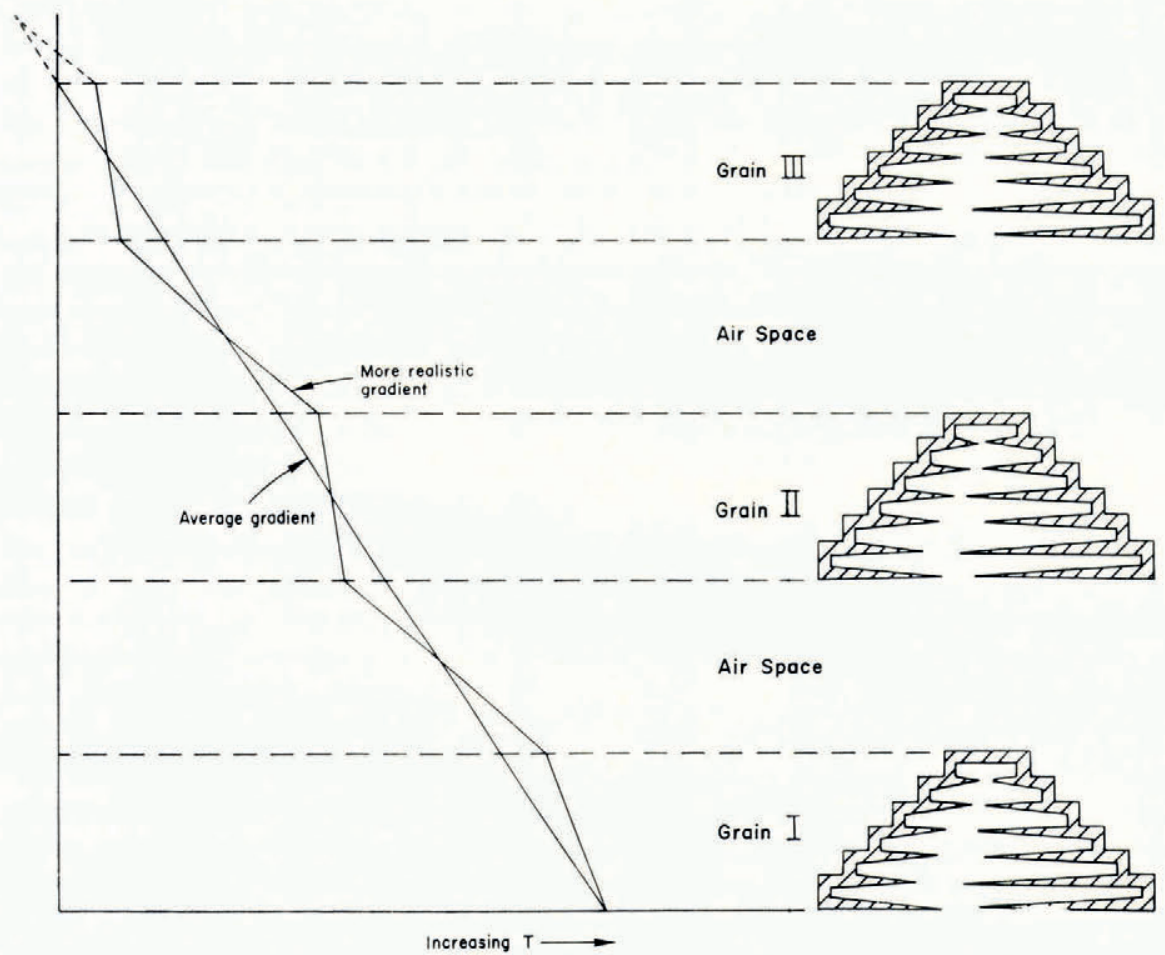

Fig. 3. A schematic representation of the temiperature gradient during temperature-gradient metamorphism.

grow larger, and large, hollow pyramids and lattice grains may be found (Akitaya, 1967). This is the familiar form of mature depth hoar (III. B. I-2).

In each of these sequences of temperature-gradient metamorphism, faceted crystals first appear, then small and poorly formed stepped surfaces. Eventually, after most of the water molecules have passed through the vapor phase, fully developed depth hoar with its characteristic stepped surfaces is formed. Our classification distinguishes the visible stages of metamorphism at which approximately $<25 \%, 25 \%-75 \%$, and $>75 \%$ of the water molecules have passed through the vapor phase.

\section{Firnification}

The process of equi-temperature metamorphism, whether or not it has been preceded by temperature-gradient metamorphism or aided by melt, can carry rounding and bonding of 
snow grains and consequent densification only to a well-defined limit. This limit is reached when the grains tend to become spheres and the density approaches that of randomly packed uniform ice spheres $\left(580-600 \mathrm{~kg} / \mathrm{m}^{3}\right)$. Anderson and Benson ( 1963 ) have pointed out that snow properties change abruptly at approximately this density range. Snow by our definition then becomes firn, and the metamorphic process which leads to further densification and change in grain character is known as firnification.

\section{Melt-freeze metamorphism}

Initially, firnification in temperate climate takes place largely by "melt-freeze metamorphism". When snow temperature rises to the freezing point, equi-temperature metamorphism is strongly accelerated. Melting can ensue, and the snow cover soon becomes isothermal for all practical purposes. When this happens early in the season, as with a short thaw, it may not affect the whole snow cover. Snow grains become rounded and meltwater is trapped between grairs by capillary action. Refreezing can cause the retained melt water to accrete on the grains, especially at the intergranular contacts. A single melt-freeze cycle leads to limited melt-freeze metamorphism (IV.A. I). Repeated cycles lead to a rise in ice density and a rapid gain in mechanical strength. Individual grains still retain both their crystallographic and physical identity (grain and crystal boundaries often coincide). Bulk specimens usually fracture along grain boundaries. In the normal firn of temperate glaciers, ice accretes by refreezing of melt water at least once each year and often more frequently (IV. A. 2).

\section{Pressure metamorphism}

As the firn is buried by successive annual accumulations, pressure gradually supplants melt-freeze as the dominant metamorphic agent. Pressure deforms and rearranges the ice grains into a compact mass of increasingly higher density. Volume diffusion within the grains also plays a part in this densification (Hobbs and Radke, i967). Overburden pressure also accelerates the earlier stages of snow metamorphism, but this does not affect the divisions of our present classification. As a result of pressure metamorphism in firn, the individual grains become difficult to distinguish, the identity between grain and crystal boundaries becomes less frequent, and ice fractures under stress across the grains as well as at the grain boundaries (IV. B. 2). The density range is approximately $700-800 \mathrm{~kg} / \mathrm{m}^{3}$.

At a density of $800-830 \mathrm{~kg} / \mathrm{m}^{3}$ the pore volume of firn becomes non-communicating, and the firn by definition becomes glacier ice (IV. B. 2). It can be further densified only by compression or expulsion of the pore spaces.

\section{Combined sequences}

As weather conditions change, the course of snow metamorphism must change. Throughout its history, a particular snow layer will be subjected to a complicated combination of the types of metamorphism. For example, suppose new snow falls with little wind action at relatively high temperatures (I.A). The conditions do not change for several days and the layer is subjected to equi-temperature metamorphism which proceeds rapidly because of the high temperature. It reaches stage II. A. 2. Next, the air temperature falls and a significant temperature gradient is established in the layer. Temperature-gradient metamorphism begins, and the snow reaches stage III. B. I. At this point, warming temperatures and another snowfall greatly reduce the gradient so that the layer resumes equi-temperature metamorphism at a more advanced level (II. B. 2) which further increases grain size and re-establishes the bonds which were weakened by temperature-gradient metamorphism. Then, above-freezing temperatures cause the layer to become permeated with melt water (IV.A. I). The layer is finally destroyed by melting. 
It will be easy for anyone familiar with snow metamorphism to construct other plausible examples. In the field it is often possible to deduce a layer's metamorphic history from grain types and the layer's properties. For example, rebonded depth hoar must have gone through temperature-gradient metamorphism and then equi-temperature metamorphism. In complex cases, a knowledge of past weather conditions and of the layer's history will be necessary to determine its classification.

\section{The classification of SNOW metamorphism}

I. Unmetamorphosed snow

A. No wind action: Many fragile snow crystal forms easily distinguishable; little difference from snow in air

We recommend that subclassifications be made in accordance with the system of Magono and Lee $(1966)$.

B. Wind blown: Shards and splinters of original snow crystals; parts of original forms may be recognizable but whole forms very uncommon

Magono and Lee's (1966) classifications.

C. Surface hoar (Fig. 4).

II. Equi-temperature metamorphism

A. Decreasing grain size

I. Beginning: original snow crystal shapes recognizable, but corners show rounding and fine structure has disappeared (Fig. 5).

2. Advanced: very few indistinct plates or fragments recognizable; grains show distinct rounding (Fig. 6).

B. Increasing grain size

I. Beginning: no original snow crystal shapes recognizable; grains show a distinct equi-dimensional tendency; a few, indistinct facets may be visible (Fig. 7).

2. Advanced: larger equi-dimensional grains present; a strong tendency toward uniform grain size; faceting generally absent (Fig. 8).

III. Temperature-gradient metamorphism

A. Early: The result of a strong thermal gradient on new-fallen snow; associated with the first snowfalls of the season.

I. Beginning: angular or faceted grains common; stepped surfaces not visible (Fig. 9).

2. Partial: medium-sized angular grains predominate; poorly formed steps visible (Fig. I0).

3. Advanced: medium to large angular grains predominate; well-developed facets and steps visible; a few filled or hollow cups may be found (Fig. I I).

B. Late: The result of a strong thermal gradient acting on snow in the later stages of equi-temperature metamorphism.

I. Beginning: medium to large angular or faceted grains predominate; some stepped surfaces visible (Fig. 12).

2. Advanced: large grains predominate; many very fragile hollow cups or lattice grains; very deep steps (Fig. 13). 


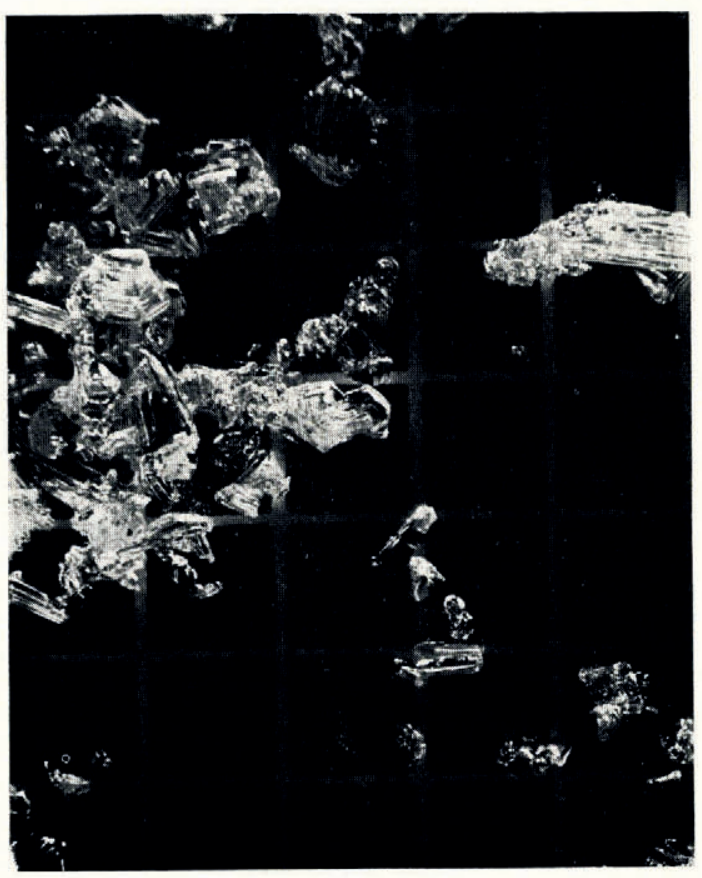

Fig. 4. I. C. Unmetamorphosed surface hoar (2 mm grid). U.S. Forest Service photograph.

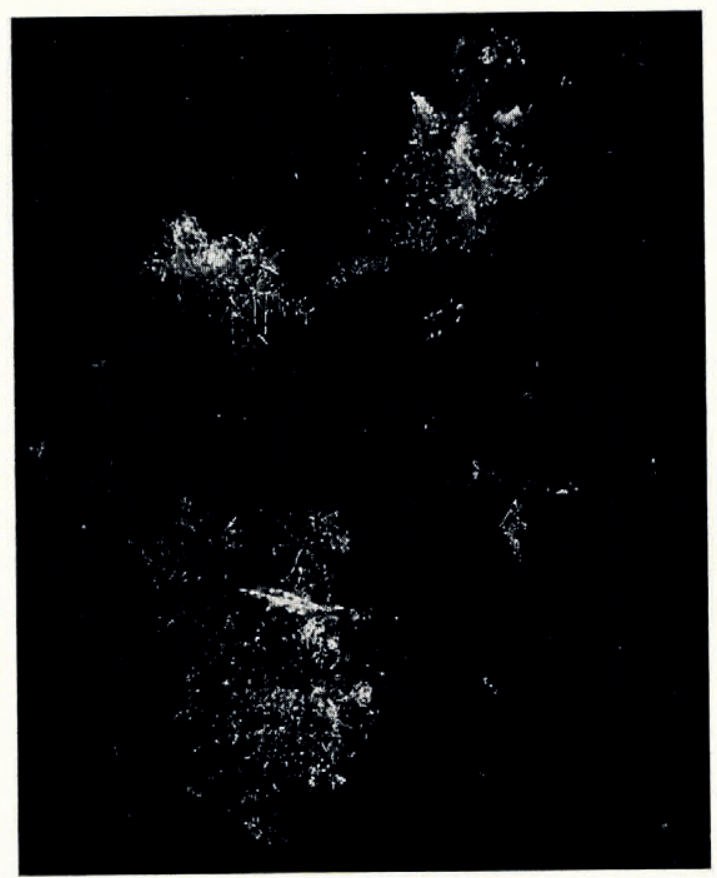

Fig. 5. II. A. 1. Beginning, decreasing grain size, equi-temperature metamorphism. U.S. Forest Service phatograph. 


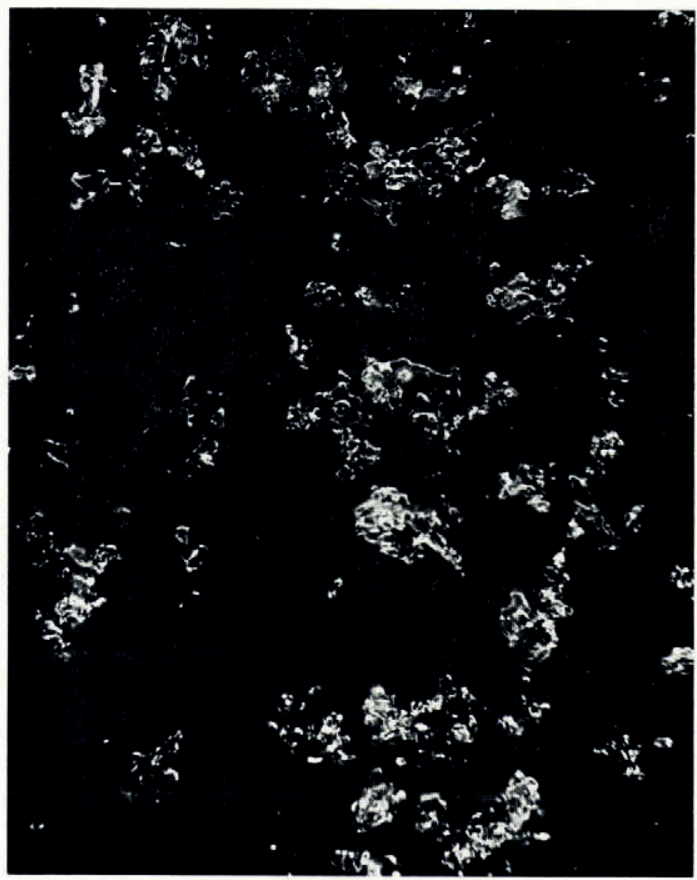

Fig. 6. II. A. 2. Advanced, decreasing grain size, equi-temperature meiamorphism. U.S. Forest Service photograph.

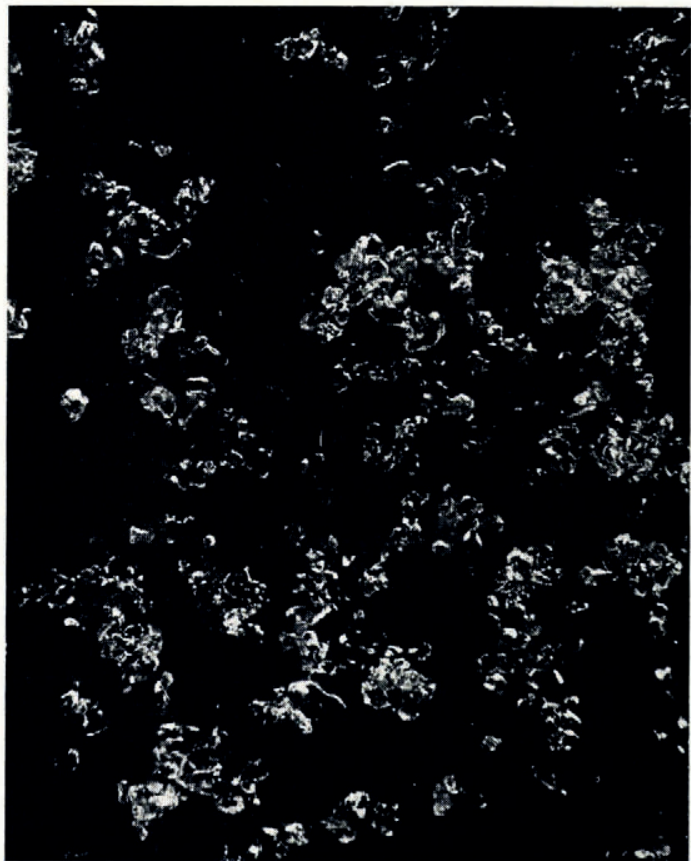

Fig. 7. II. B. I. Beginning, increasing grain size, equi-temferature metamorphism. U.S. Forest Service photograph. 


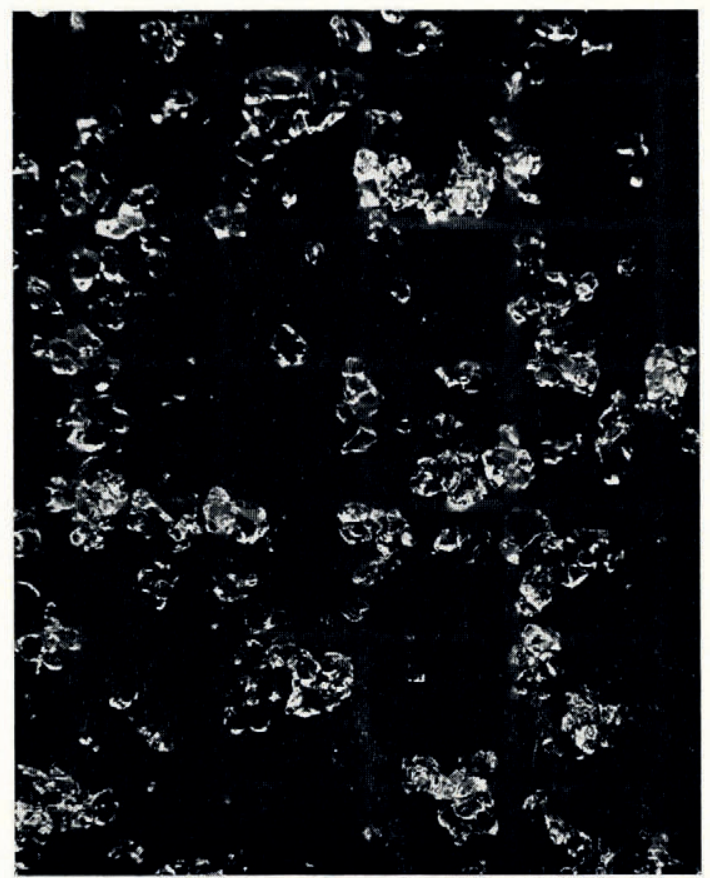

Fig. 8. II. B. 2. Advanced, increasing grain size, equi-temperature metamorphism. U.S. Forest Service photograph.

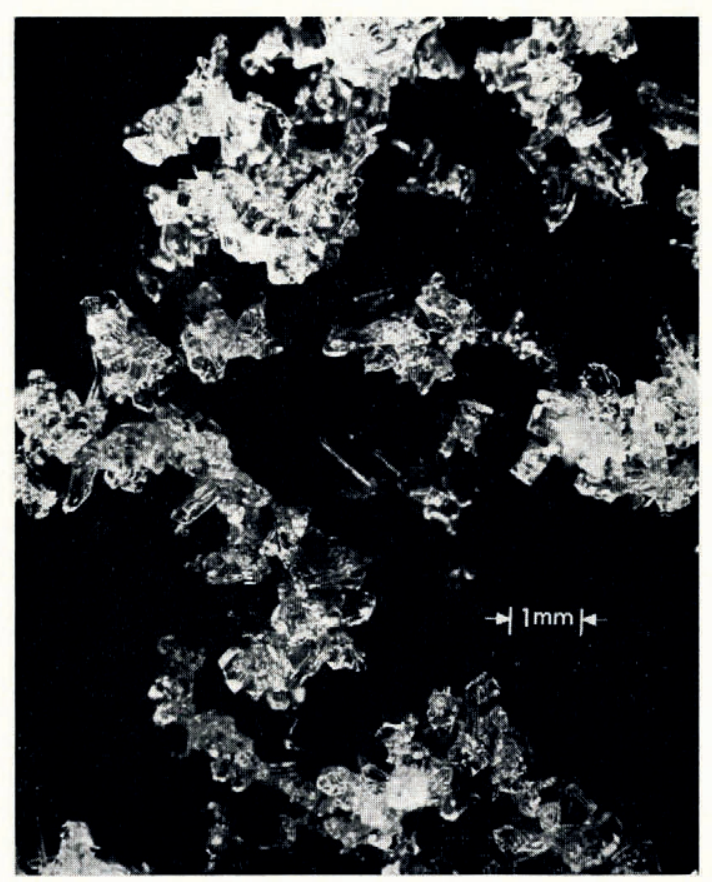

Fig. 9. III. A. I. Beginning, early, temperature-gradient metamorphism. U.S. Forest Service photograph. 


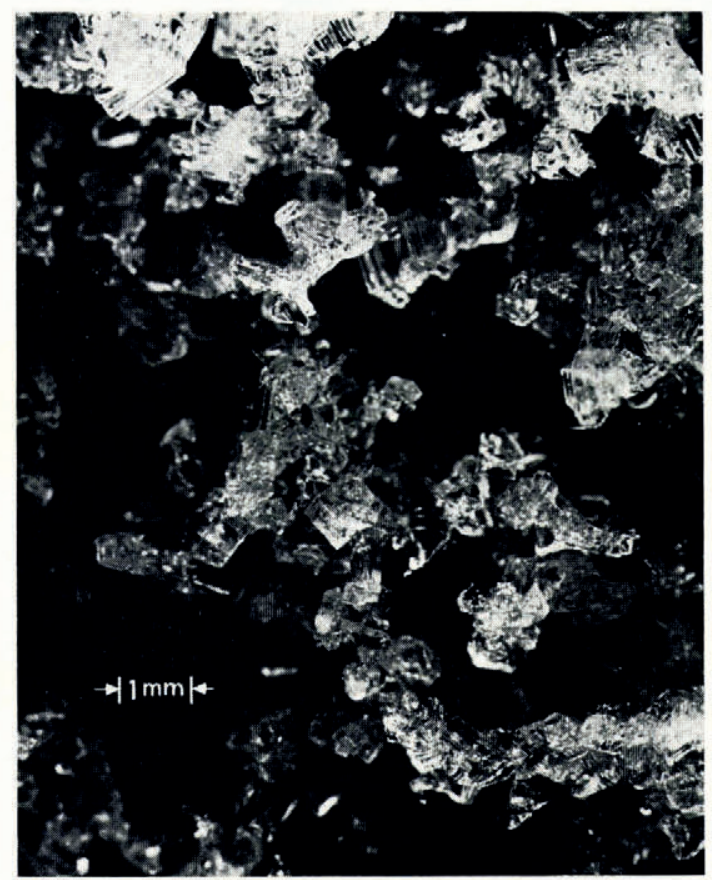

Fig. 10. III. A. 2. Partial, early, temferature-gradient metamorphism. U.S. Forest Service photograph.

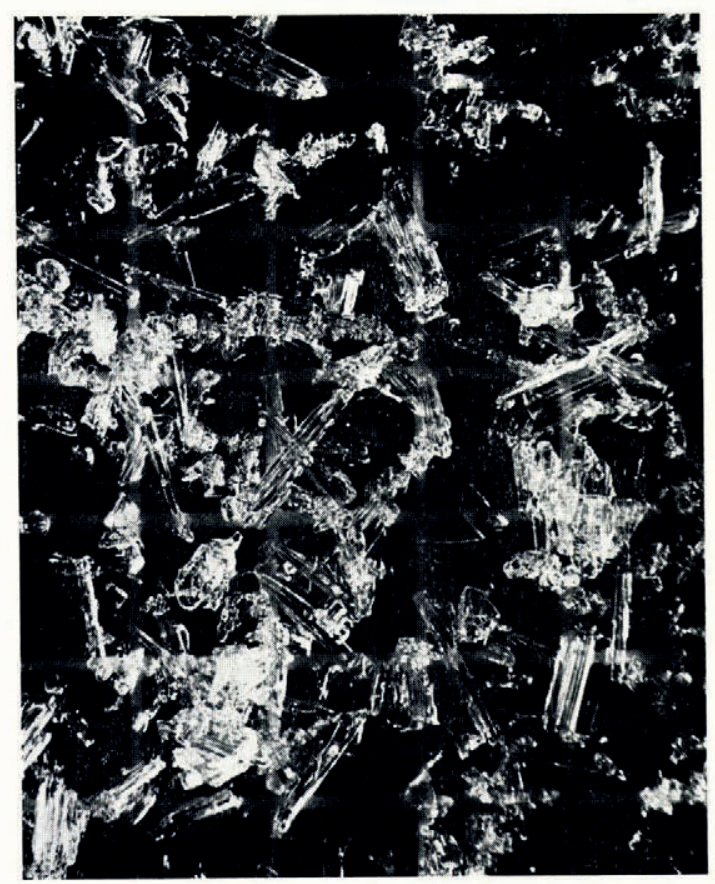

Fig. 11. III. A. 3. Advanced, early, temperature-gradient metamorphism. U.S. Forest Service photograph. 


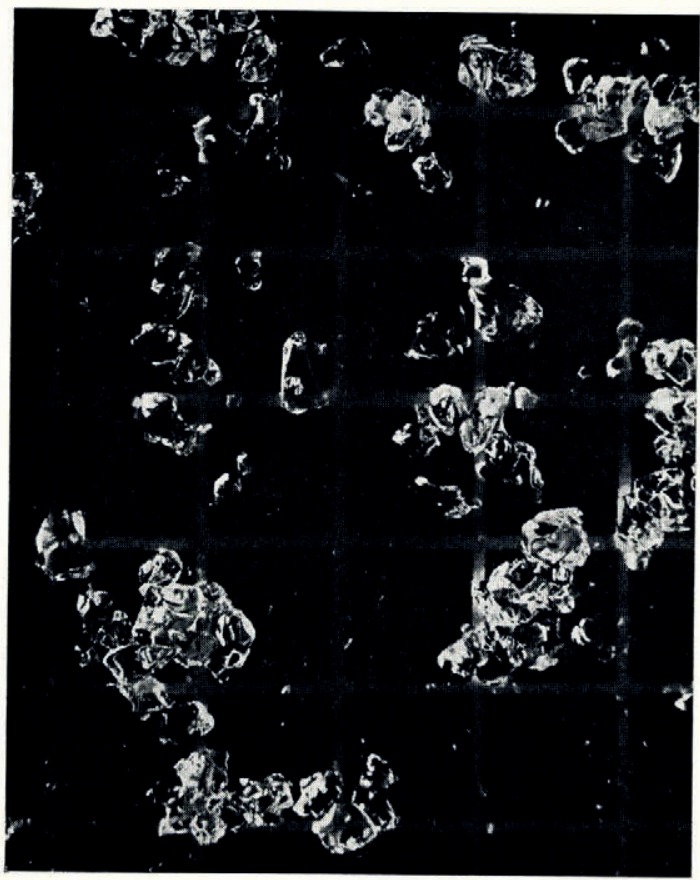

Fig. I2. III. B. I. Beginning, late, temperature-gradient metamorphism. U.S. Forest Service photograph.

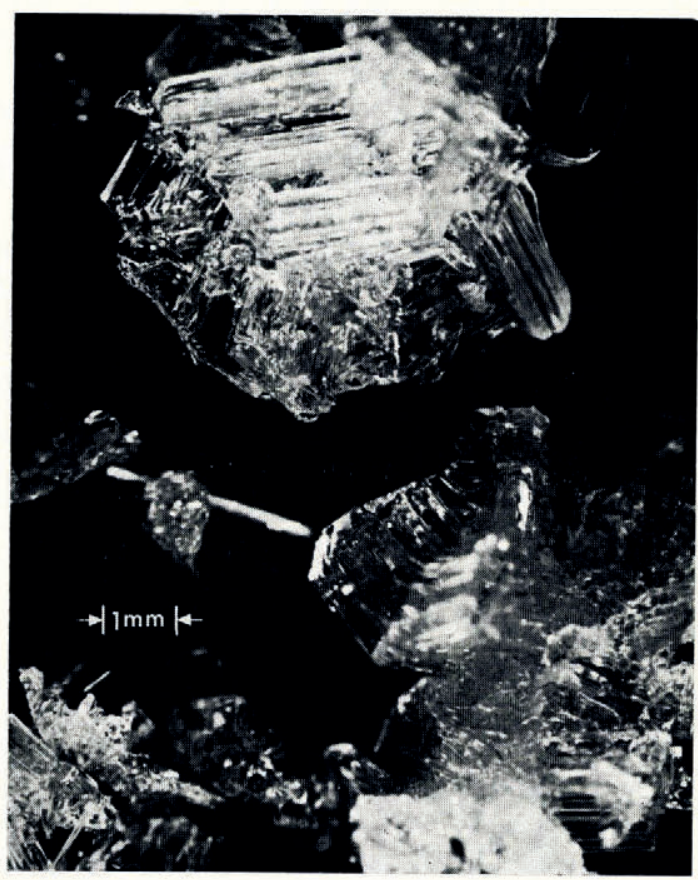

Fig. 13. III. B. 2. Advanced, late, temperature-gradient metamorphism. U.S. Forest Service photograph. 


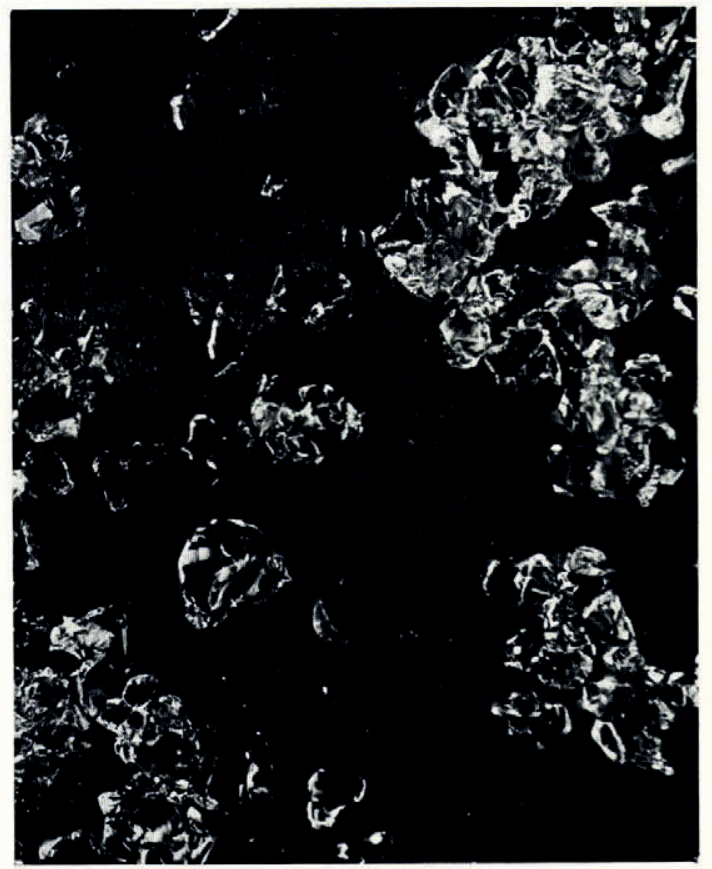

Fig. It. IV. A. I. Limited, melt-freeze, firnification. U.S. Forest Service photograph.

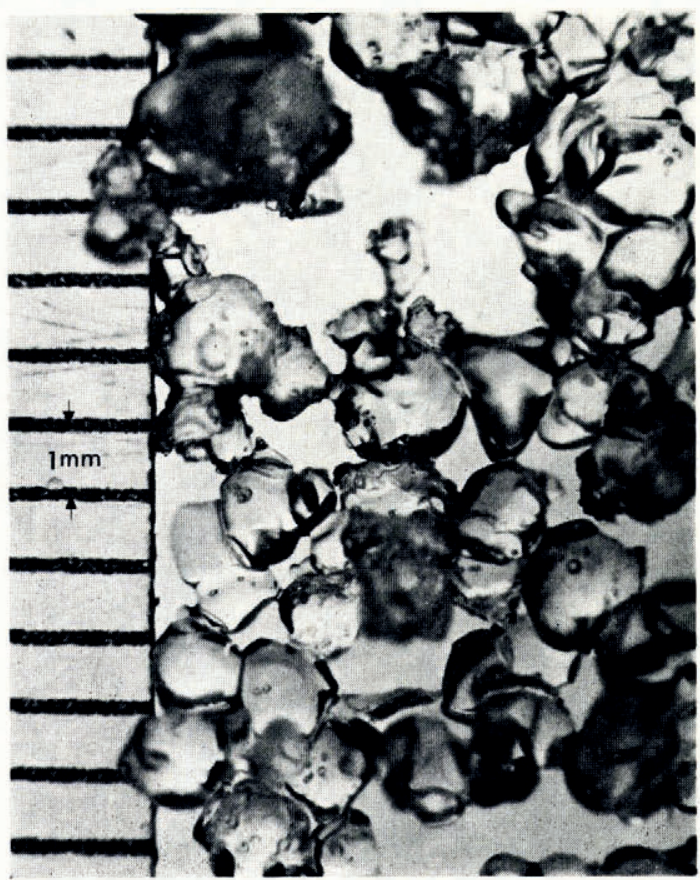

Fig. I.5. IV. A. 2. Advanced, melt-freeze, firnification. U.S. Forest Service photograph. 


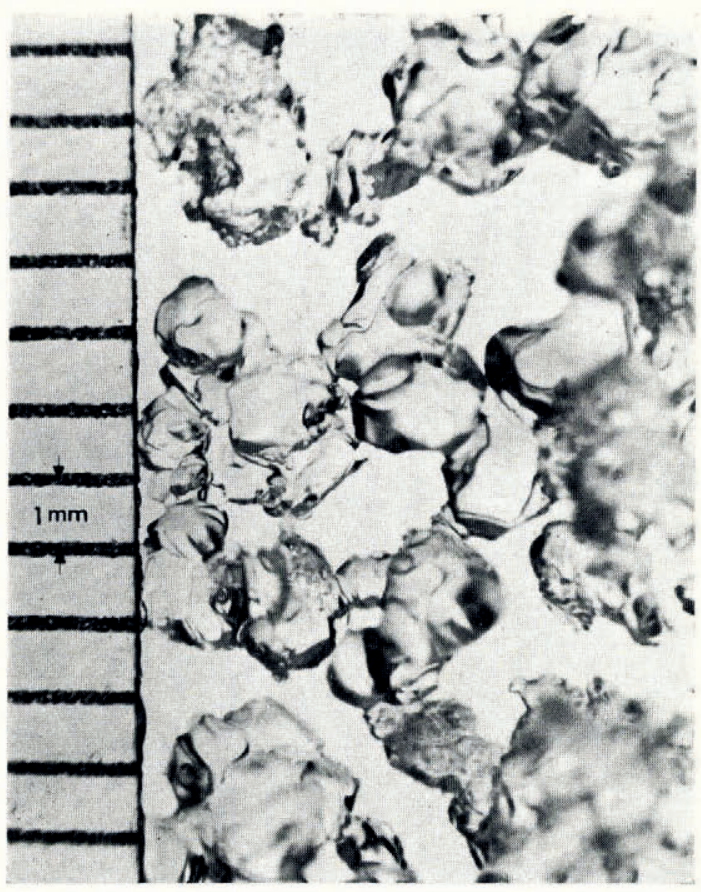

Fig. I6. IV. B. I. Beginning, pressure, firnification. U.S. Forest Service photograph.

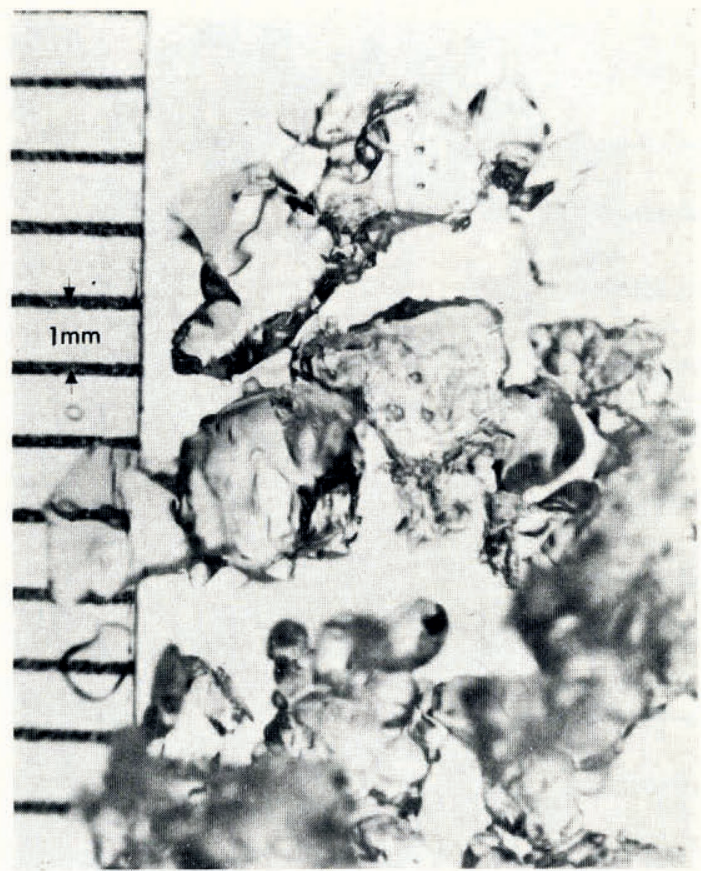

Fig. I7. IV. B. 2. Advanced, pressure, firnification. U.S. Forest Service photograph. 
IV. Firnification

A. Melt-freeze metamorphism

I. Limited: single thaw-freeze cycle and limited gain in ice density (Fig. I4).

2. Advanced: repeated thaw-freeze cycles and appreciable gain in density and mechanical strength; density range $600-700 \mathrm{~kg} / \mathrm{m}^{3}$ (Fig. I 5).

B. Pressure metamorphism

I. Beginning: grains deformed and rearranged by pressure; density range $700-800$ $\mathrm{kg} / \mathrm{m}^{3}$ (Fig. I6).

2. Advanced: pore spaces become non-communicating; permeability zero; density range $800-830 \mathrm{~kg} / \mathrm{m}^{3}$ (Fig. I 7).

IS. received 9 May 1969

\section{REFERENCES}

Akitaya, E. 1967. Some experiments on the growth of depth hoar. (In Ōura, H., ed. Physics of snow and ice: international conference on low temperature science. ... I966. . . Proceedings, Vol. I, Pt. 2. [Sapporo], Institute of Low Temperature Science, Hokkaido University, p. 71 13-23.)

Anderson, D. L., and Benson, C. S. $195_{3}$. The densification and diagenesis of snow. (In Kingery, W. D., ed. Ice and snow; properties, processes and applications: proceedings of a conference held at the Massachusetts Institute of Technology, February 12-16, 1962. Cambridge, Mass., M.I.T. Press, p. 391-41 1.)

Bader, H., and others. 1939. Der Schnee und seine Metamorphose, von H. Bader, R. Haefeli, E. Bucher, J. Neher, O. Eckel, C. Thams, P. Niggli. Beiträge zur Geologie der Schweiz. Geotechnische Serie. Hydrologie, Lief. 3. [English translation: U.S. Snow, Ice and Permafrost Research Establishment. Translation 14, 1954.]

Canada. National Research Council. 1954. The international classification for snow (with special reference to snow on the ground) issued by the Commission on Snow and Ice of the International Association of Hydrology. Canada. National Research Council. Associate Committee on Soil and Snow Mechanics. Technical Memorandum No. 31.

Eugster, H. P. 1952. Beitrag zu einer Gefügeanalyse des Schnees. Beiträge zur Geologie der Schweiz. Geotechnische Serie. Hydrologie, Lief. 5 .

Hobbs, P. V., and Mason, B. J. I964. The sintering and adhesion of ice. Philosophical Magazine, Eighth Ser., Vol. 9, No. 98, p. $181-97$.

Hobbs, P. V., and Radke, L. F. 1967. The role of volume diffusion in the metamorphism of snow. Journal of Glaciology, Vol. 6, No. 48, p. 879-91.

Magono, C., and Lee, C. W. 1966. Meteorological classification of natural snow crystals. Fournal of the Faculty of Science, Hokkaido University. Ser. 7, Vol. 2, No. 4, p. $321-35$.

Quervain, M. R. de. 1958. On metamorphism and hardening of snow under constant pressure and temperature gradient. Union Géodésique et Géophysique Internationale. Association Internationale d'Hydro!ogie Scientifique. Assemblée générale de Toronto, 3-14 sept. 1957, Tom. 4, p. 225-39.

Yosida, Z., and others. 1955. Physical studies on deposited snow. I. Thermal properties, by Z. Yosida and colleagues. Contributions from the Institute of Low Temperature Science, No. 7, p. 19-74. 